\title{
The Mediating Effect of Quality of Life on Tourism Impact and Support Attitude in Alishan Tribes
}

\author{
Hsiao-Ming Chang1, Chiu-Hui Hung'2, Yen-Chen Huang3 \\ ${ }^{1}$ School of Physical Education, Putian University, Putian, China \\ ${ }^{2}$ Department of Tourism, Leisure and Entertainment Management, Tatung Institute of Technology, Taiwan \\ ${ }^{3}$ Taipei University of Marine Technology, Taiwan \\ Email: 1815649662@qq.com, chiuhui@ms2.ttc.edu.tw, cy5321@yahoo.com.tw
}

How to cite this paper: Chang, H.-M., Hung, C.-H. and Huang, Y.-C. (2019) The Mediating Effect of Quality of Life on Tourism Impact and Support Attitude in Alishan Tribes. Open Journal of Applied Sciences, 9, 857-869.

https://doi.org/10.4236/ojapps.2019.912069

Received: November 18, 2019

Accepted: December 10, 2019

Published: December 13, 2019

Copyright $\odot 2019$ by author(s) and Scientific Research Publishing Inc. This work is licensed under the Creative Commons Attribution International License (CC BY 4.0).

http://creativecommons.org/licenses/by/4.0/

\begin{abstract}
The purpose of this study was aimed to analyze the effect of indigenous people's perceived impact of tourism development on tribal quality of life and the support attitude toward tourism development. The research subjects were indigenous people who were at least 20 years old and came from one of eight Alishan tribes in Taiwan. This study conducted an investigation by random sampling, a total of 850 questionnaires were distributed and obtained 827 valid questionnaires. The valid return rate was $97.29 \%$. Statistical analysis was performed on the valid questionnaires using descriptive statistics and partial least squares (PLS). According to the analytical result, Alishan indigenous people feel the negative environmental impact brought by tourism is the highest, but in terms of quality of life, they also maintain of nature and culture. When the positive economic, environmental, and sociocultural impact of tourism is higher, tribal quality of life and indigenous people's support attitude toward tourism development will be more significant; however, when the negative economic, environmental, and sociocultural tourism impact is higher, tribal quality of life will be lower and indigenous people will tend to resist tourism development. Quality of life was found to be a moderator between tourism impact and support attitude toward development. This study proposed suggestions for indigenous tribes and the government to develop the tourism sector and introduced specific research directions for future tribal tourism researchers.
\end{abstract}

\section{Keywords}

Tourism Impact, Quality of Life, Support Attitude, Indigenous People, Alishan Tribe 


\section{Introduction}

Indigenous culture is an important cultural asset in Taiwan and part of its cultural heritage. However, due to the impact of modern life, traditional tribal culture has been influenced. In addition, the difficulty of traditional life and obstacles to finding jobs have resulted in the outward migration of tribes [1] [2]. Alishan is one of the important places for the Taiwan Tourism Bureau to promote in-depth tourism for indigenous tribes. It boasts not only natural forest resources but also abundant Tsou indigenous culture, and thus has become internationally well-known. In recent years, due to the increase in tourism, the number of national and foreign tourists visiting the indigenous tribes of Alishan on holidays has continued to increase. Many tribes operate B\&B hotels and allow tourists to experience Tsou culture. Because of tourism development, indigenous people in Alishan tribes have obtained more job opportunities. According to studies related to Alishan tribes, tourism results in not only a positive economic impact but also negative economic, environmental, and social culture impacts [3].

Research on tourism impact is valued by researchers in Taiwan and internationally, who have realized that the impact caused by tourism influences people's quality of life [4] [5]. Nevertheless, research on tourism impact for indigenous tribes lacks study on the impact on quality of life. Andereck, Valentine, Vogt and Knopf [6] argued that the tourism industry not only improves quality of life but also allows communities to realize an ideal living environment. Therefore, tourism not only leads to positive and negative impacts on tourist areas but also influences local quality of life [7] [8] [9]. Therefore, it is very important for local residents whether they support tourism. As to residents' attitude toward tourism development, according to the analysis of Nunkoo, Smith and Ramkissoon [10], there have been hundreds of international studies on this issue in the past 30 years. Apparently, tourism development leads to positive and negative effects, and thus the support of residents in tourist areas is extremely important. Residents' support attitude to tourism development [11] is a key criterion for local development of the tourism industry and governmental construction of tourism policy [10]. It is also the most important factor of the sustainable development of communities [12].

Nevertheless, as suggested by Andereck et al. [6], most tourism studies neglect quality of life and tend to focus on impact perception and support attitude. In fact, although the impact of tourism on quality of life and on local areas seems similar, it is different. Research on impact has been concerned about the effect of tourism development on local areas and individuals' agreement and support; as to quality of life, studies have analyzed the satisfaction of individuals and families on life [13]. Uysal, Sirgy, Woo and Kim [8] stated that most studies on tourism impact focus on the impact of tourism on destinations (economic, environmental, and social culture impact) and residents' support attitude, but they do not pay attention to the relationship between quality of life and tourism impact. 
Thus, tourism development could be adopted as a dependent variable to analyze the moderating effect of quality of life. According to the backgrounds and questions of this study, the following goals were proposed: 1) To analyze the perceived effect of tourism impact by indigenous people in Alishan on quality of life. 2) To analyze effects of tourism impact and quality of life perceived by indigenous people in Alishan on support attitude toward tourism development. 3) To analyze the moderating effect of quality of life between tourism impact and indigenous people's support attitude toward tourism development.

\section{Research Method}

\subsection{Research Framework and Hypothesis}

Previous studies have demonstrated the correlation between tourism impact and residents' support attitude. Residents' attitude to support tourism is influenced by the economic benefits resulting from tourism [14] [15]. In fact, numerous studies have demonstrated the positive and negative impact of tourism on tourist destinations and the influence on residents' support attitude towards tourism development. For instance, Cascante [16] explored the tourism impact on quality of life in the rural communities of Costa Rica. He found that quality of life is influenced by different types of tourism impacts and that the impact on quality of life in the communities is different. The said study demonstrated that in different communities, quality of life will be improved or destroyed. Improvement of quality of life is associated with ownership and development of local communities and activities in the tourism industry. According to the research of Kim, Uysal and Sirgy [17], tourism impact influences living fields which affect overall life satisfaction. Furthermore, the research demonstrated that different phases of tourism development moderate the residents' perceived impact and living fields. Numerous empirical studies have explored the relationship between residents' tourism impact perception and attitude towards tourism development. According to research findings of Perdue, Long and Allen [18], residents' tourism impact perception is significantly associated with attitude towards tourism development. Sirakaya, Teye and Sonmez [19] stated that residents' tourism impact perception influences local support for tourism development. When residents' perceived positive tourism impact is more significant, they will be more likely to support tourism industry. Ko and Stewart [20] studied residents' tourism impact perception and attitude and realized that residents' positive cognition of tourism impact directly and positively influences support toward tourism, while a negative cognition of tourism impact negatively influences support for tourism. Yu [9] studied residents in Indiana State's Orange County and recognized that the tourism impact degree is associated with the tourism-related community quality of life (TCQOL). Economic benefits, social culture benefits, negative social culture impact, negative environmental impact, and TCQOL all influence residents' support attitude toward tourism development. Usher and Kerstetter [21] explored tourism impact on residents' quality of life in Las Sali- 
nas, a popular surfing area in Nicaragua, and recognized that local government and residents can effectively control negative tourism impacts. Tourism development positively influences quality of life. Bakri and Jaafar [4] studied 398 residents of Langkawi Island in Malaysia regarding the effect of tourism development on local quality of life (affective welfare, community welfare, safety and health welfare, material well-being, and living expenditures) and realized that tourism development positively influences local quality of life. Noticeably, residents positively interact with tourists and local governments are willing to provide positive feedback on local infrastructure and facilities. Finally, according to the suggestion of Uysal, Sirgy, Woo \& Kim [8] in their research of tourism impact, support attitude toward tourism development could be adopted as a dependent variable to analyze the moderating effect of quality of life. Thus, based on above, this study proposed the following six hypotheses, as shown in Figure 1.

H1: Indigenous people's perceived positive tourism impact positively influences the quality of life of the tribe.

$\mathrm{H} 2$ : Indigenous people's perceived negative tourism impact negatively influences the quality of life of the tribe.

H3: Indigenous people's perceived that the impact of tourism is positive, their attitude towards the development of tribal tourism is higher.

H4: Indigenous people's perceived that the impact of tourism is negative, their attitude towards the development of tribal tourism is lower.

H5: Indigenous people's perceived quality of life of the tribe influences the support attitude toward tourism development.

H6: Quality of life moderates the relationship between tourism impact and indigenous people's support attitude toward tourism development.

\subsection{Research Area}

Alishan Township is located in the east of Chiayi County in Taiwan. It is a mountainous area with elevation of 360 to 3952 meters. The Tsao indigenous tribes in Alishan, including the Dabang, Tefuye, Leye, Laiji, Lijia, Shanmei,

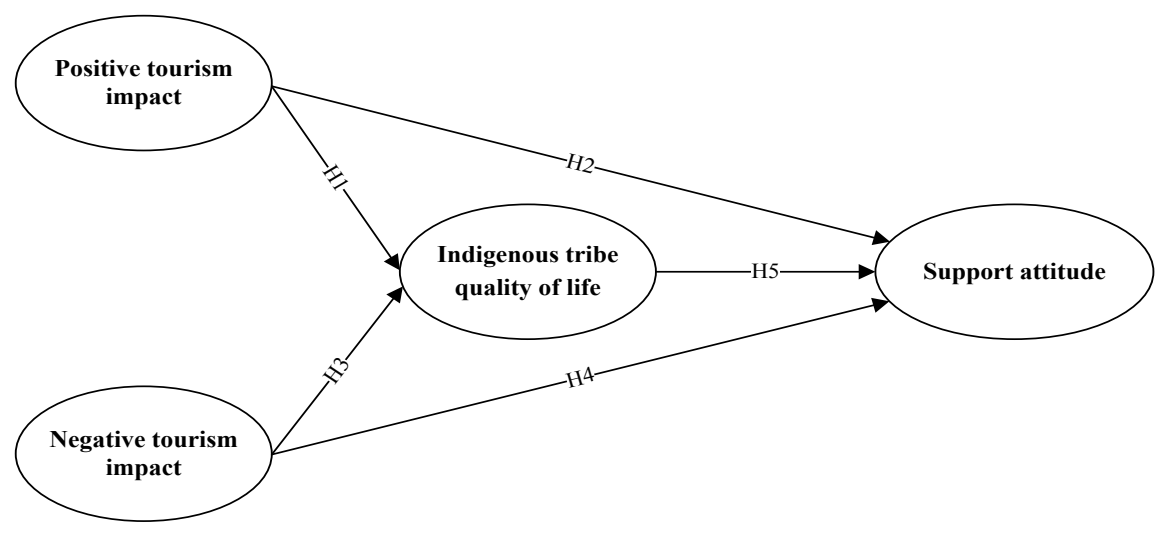

Figure 1. Research framework. 
Xinmei and Chashan tribes. After the foundation of Alishan National Scenic Area, the government not only began to actively promote Tsou culture tourism but also the features of different tribes. The Leye tribe is featured by mountain tea, coffee, and diverse ecological trails and ancient roads, while Dabang and Tefuye feature men's communal buildings, known as kuba, which are unique buildings in these tribes. In the Laiji tribe, there are several ancient trails with abundant ecological systems. However, the external access is inconvenient and is located far from Alishan Highway. As to the three villages in the south, the Xinmei tribe is based on organic agriculture and the Shanmei tribe is well-known due to the Danayiku Ecology Park. The Chashan tribe is the southernmost village of Alishan Township, and its main features are wooden twitch grass pavilions and rich eco-resources in the surroundings. The Laiji tribe is located at the bottom of Ta Mountain, the holy mountain of Tsou, and its motto is wild boar and handicrafts based on Tsou culture.

\subsection{Research Subjects and Sampling}

According to the review of Nunkoo, Smith and Ramkissoon [10] on 140 papers related to tourism impact published in Annals of Tourism Research, Tourism Management and Journal of Travel Research from 1984 to 2010, future researchers should not only combine multiple statistical methods but also conduct quantitative research in order to completely recognize residents' attitude. Therefore, this study adopted a questionnaire survey and treated indigenous people living in the eight tribes of Alishan National Scenic Area as subjects. Based on households, it conducted a general survey and investigated one indigenous person aged at least 20 in every household of each tribe. During weekdays there were usually only elderly residents and children in the tribes because the young people mostly worked or studied in the cities, therefore this study conducted the surveys on holidays. The investigation lasted from February 11 to May 25, 2018. Questionnaires were distributed to $50 \%$ of the population aged 20 years old or above in the Dabang, Tefuye, Leye, Laiji, Lijia, Shanmei, Xinmei and Chashan tribes. A total of 850 questionnaires were distributed and 827 valid questionnaires were returned, including 96 questionnaires from Dabang, 92 from Tefuye, 108 from Shanmei, 90 from Liaji, 84 from Chashan, 82 from Xinmei, 204 from Leye, and 71 from Laiji were retrieved. The valid return rate was $97.29 \%$.

\subsection{Research Questionnaire}

The research questionnaire included four parts. First is the tourism impact cognition scale, which has 40 questions and 6 factors. It aimed to explore indigenous people's perceived positive and negative economic, environmental, and sociocultural impact on the tribes resulting from tourism development. The design of the sub-scales was based on the tourism impact towards tribes' research [1] [2] [3] [22] [23].

Part 2 of the questionnaire was a scale on the quality of life of indigenous tribes and included 34 items and seven factors: sense of tribe, maintenance of na- 
ture and culture, public facilities, taxation and subsidy, economic power, public security, and tribal life. The scale was designed according to the scales of quality of life of Andereck and Nyaupane [7], Sirgy and Cornwell [24], and Sirgy, Rahtz, Cicic and Underwood [25]. The scales developed by previous scholars mostly focus on communities and the items do not match the lives of indigenous tribes in Taiwan. The researcher used the experience of training volunteer guides in the eight tribes to understand the tribal situations. Thus, in addition to the previous studies, the researcher designed the scale of the quality of life according to practical experience.

Part 3 of the questionnaire was the scale of attitude towards tourism development. The scale included five items and aimed to explore indigenous people's support and satisfaction with tourism development in the tribes. The scale was based on the research of Gursoy, Jurowski and Uysal [15], as well as the instrument developed by Lankford and Howard [11]. Scores for the three scales ranged from 1 to 5 , with answers ranging from "strongly agree" to "strongly disagree". The last part is the demographic variables background of indigenous people, including gender, marital status, age, education level, monthly income, and living tribe.

\subsection{Data Analysis}

As to the valid questionnaires retrieved, the steps of the statistical analysis were as follows. First, SPSS for Windows 22.0 was used to analyze the distribution of the indigenous people's demographic variables through frequency distribution and percentages of the descriptive statistics. Second, Warp PLS 6.0 and partial least squares (PLS) was used to analyze the reliability and validity of the scales of tourism impact, quality of life of indigenous tribes, and support attitude toward tourism development, as well as the causal relationships among variables. Measurement of reliability and validity was performed using the composite reliability (CR) and Cronbach's $\alpha$, which needed to be equal to or more than 0.70 [26] [27]. The convergent validity of the latent variables was validated using factor loadings of the observed variables that were equal to or more than 0.50 [28]. In addition, for the discriminant validity, this study adopted the standard of Chin [29], who proposed that the square roots of the average variances extracted of the latent variables should be higher than the covariance relationship between one latent variable and other latent variables in the model, in addition, that the square root of the AVE should be at least more than or equal to 0.70 [30]. The model structural relation analysis (hypothesis model) depended on the statistical significance of the standardized path coefficients and model's explained power, which was measured by $\mathrm{R}^{2}$ [28].

\section{Results}

\subsection{Characteristic Analysis of the Valid Samples}

Among the 827 valid questionnaires retrieved, 368 were males (44.5\%) and 459 were females (55.5\%). As to marital status, 484 were married (58.6\%) and 342 
were unmarried (41.4\%). As to age, most of the respondents were aged 21 - 30 (232 subjects; $28.1 \%$ ). As to education, most of them had graduated from senior high schools and vocational schools (475 subjects; $57.4 \%$ ). As to occupation, most of the respondents worked in the service industry (279 subjects; $33.7 \%$ ). As to monthly income, most of the respondents (503 subjects; $60.8 \%$ ) earned below NTD 25,000 (USD 833).

In terms of tourism impact, the indigenous people of Alishan felt the impact brought by tourism, the negative environmental impact was the highest $(\mathrm{M}=$ $26.76, \mathrm{SD}=4.23)$, followed by the positive sociocultural impact $(\mathrm{M}=25.33, \mathrm{SD}=$ $4.30)$, the third was the negative sociocultural impact $(M=25.11, S D=3.47)$, the fourth was the positive economic impact $(M=24.31, S D=3.82)$, the fifth was the negative economic impact $(M=20.54, S D=3.39)$, and the last was the positive environment impact $(\mathrm{M}=0.31, \mathrm{SD}=4.33)$. In terms of the impact of quality of life, the order of the highest feelings of the indigenous people in Alishan is: maintenance of nature and culture $(M=15.87, S D=4.19)$, tribal life $(M=14.71$, $\mathrm{SD}=3.51)$, public facilities $(\mathrm{M}=14.66, \mathrm{SD}=3.67)$, sense of tribe $(\mathrm{M}=14.15, \mathrm{SD}$ $=2.64)$, taxation and subsidy $(\mathrm{M}=13.72, \mathrm{SD}=3.88)$, economic power $(\mathrm{M}=$ $13.12, \mathrm{SD}=2.47)$, and public security $(\mathrm{M}=12.87, \mathrm{SD}=2.11)$.

\subsection{Reliability and Validity Analysis of the Questionnaire}

\subsubsection{Scale of Tourism Impact}

According to the analytical result of the scale of positive economic impact the composite reliability was 0.81 and Cronbach's $\alpha$ was 0.72 ; as to negative economic impact, the composite reliability was 0.79 and Cronbach's $\alpha$ was 0.67 . As to positive environmental impact, the composite reliability was 0.87 and Cronbach's $\alpha$ was 0.82 ; as to negative environmental impact, the composite reliability was 0.88 and Cronbach's $\alpha$ was 0.83 . As to positive sociocultural impact, the composite reliability was 0.86 and Cronbach's $\alpha$ was 0.80 ; as to negative social culture impact, the composite reliability was 0.78 and Cronbach's $\alpha$ was 0.68 . Generally speaking, the composite reliability of the variables was more than 0.70 and met the standard. In other words, the reliability of the scale of tourism impact was acceptable. Although Cronbach's $\alpha$ for negative economic impact and negative sociocultural impact did not reach 0.70 , they were close. The composite reliability met the standard and thus was retained. In the scale, the factor loading of item 19 (enhancement of external investment) was 0.43 , the factor loading of item 25 (enhancement of sales of tribes' agricultural products) was 0.48 , the factor loading of item 26 (tourists collecting agricultural products without permission) was 0.45 , the factor loading of item 38 (tribal people working together) was 0.45 , the factor loading of item 24 (tribal people's traditional values turn to practicality) was 0.46 , and the factor loading of item 30 (commercialized traditional goods and rituals) was 0.47 . These four items were deleted.

\subsubsection{Scale of Quality of Life in Indigenous Tribes}

According to the analytical result of the scale of quality of life in indigenous tri- 
bes, the composite reliability of the factors in this scale were higher than 0.70 and matched the standard. Only public security showed a Cronbach's $\alpha$ of 0.64 . However, the composite reliability of the factor was higher than 0.70 , therefore the factor was retained. Generally speaking, the reliability of scale of quality of life was acceptable. However, the factor loading of item 3 (medical facilities of the tribe) was 0.43 and did not reach the standard of 0.50 ; therefore, the item was deleted.

\subsubsection{Scale of Support Attitude toward Tourism Development}

According to the analytical result of scale of support attitude toward tourism development, the composite reliability was 0.89 and Cronbach's $\alpha$ was 0.90 , which were higher than 0.85 and matched the standard. The results indicated that the reliability of the scale of support attitude toward tourism development was acceptable. The factor loadings of all items were at least 0.50 and revealed positive convergent validity of all factors in the scales.

\subsubsection{Analysis of Discriminant Validity}

According to analytical result shown in Table 1, the AVE of the latent variables were all higher than all the correlation coefficients in the same column and row and were higher than 0.70 , meaning they met the standard. Therefore, the measurement model of this study showed positive discriminant validity.

\subsubsection{Model Analysis}

In Figure 2, the values on the lines refer to the path coefficients as standardized regression coefficients $(\beta)$. The positive tourism impact was found to positively influence quality of life $(\beta 1=0.65, \mathrm{p}<0.05)$ and support attitude $(\beta 2=-0.24, \mathrm{p}$ $<0.05)$; thus, $\mathrm{H} 1$ and $\mathrm{H} 2$ were supported. In addition, negative tourism impact was found to negatively influence quality of life $(\beta 3=-0.24, \mathrm{p}<0.05)$; thus, H3 was supported. However, it did not influence support attitude $(\beta 4=-0.02, \mathrm{p}=$ 0.28 ). Thus, $\mathrm{H} 4$ was not supported. Finally, quality of life was found to influence support attitude $(\beta 3=-0.24, \mathrm{p}<0.05)$; thus, $\mathrm{H} 5$ was supported.

As to the explanatory power, $\mathrm{R}^{2}$ indicates the predictive power of the research model and is the percentage of the explained variance of exogenous variables to endogenous variables. When the value is higher, the predictive power is more

Table 1. Analytical results of the discriminant validity of the scales.

\begin{tabular}{ccccc}
\hline \multirow{2}{*}{ Factors } & \multicolumn{3}{c}{ Factors } \\
\cline { 2 - 5 } & Positive impact & Negative impact & Quality of life & Support attitude \\
\hline Positive impact & 0.88 & 0.03 & 0.70 & 0.62 \\
Negative impact & 0.03 & 0.87 & -0.26 & -0.06 \\
Quality of life & 0.70 & -0.26 & 0.83 & 0.44 \\
Support attitude & 0.62 & -0.06 & 0.44 & 1 \\
\hline
\end{tabular}

${ }^{*}$ Values on the diagonal line are square roots of the average variances extracted (AVE) of different dimensions. 


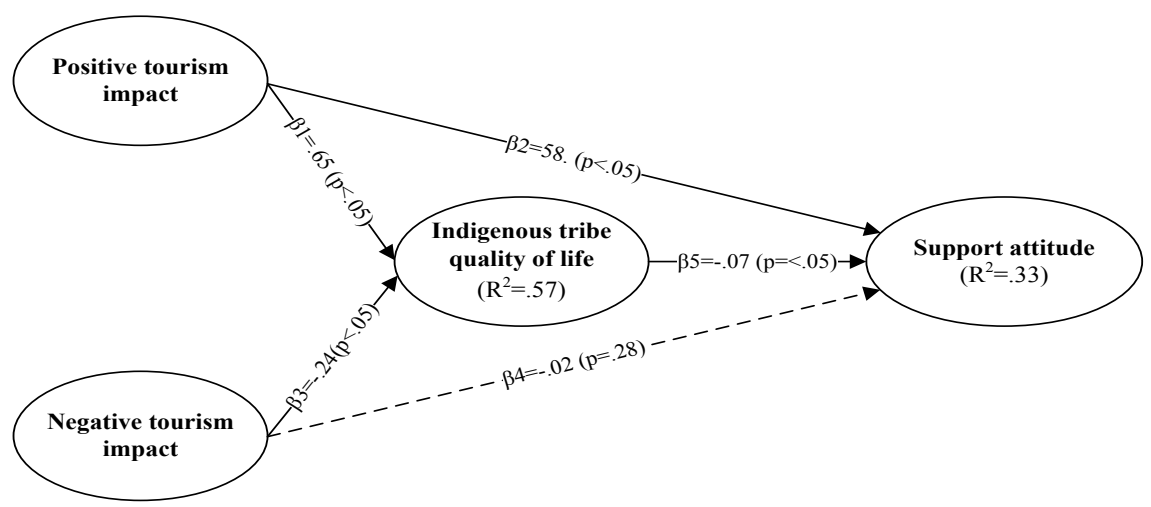

Figure 2. Result model.

significant. The research findings are shown in Figure 2. The positive tourism impact and negative tourism impact could explain 57\% of the variance of the quality of life of indigenous tribes, while positive tourism impact and quality of life of indigenous tribes could explain 33\% variance of support attitude to tourism development.

\section{Discussion, Conclusion, and Application}

\subsection{Discussion}

First of all, in terms of the impact of tourism in this study, the results show that the indigenous people feel the most negative impact on the development of tourism in Alishan tribe. This shows that the development of tourism brings noise increase, leading to the tribe become overcrowded, traffic conversation, environmental pollution, garbage increase, and natural resources destroyed. So the above results are the same as the previous research [1] [2] [3] [22] [23], that is, tourism development will bring negative impact on the local. However, since tourism development has negative development, why do indigenous people support it? The main reason is that from the perspective of social exchange theory, although indigenous people feel the negative impact of tourism, they still have a positive impact, so they still support it.

According to the analytical result, in order to develop another direction of economic development in indigenous tribes and launch tribal tourism according to indigenous culture, the Taiwan government relies on the support of indigenous peoples since they perceive the positive economic impact of job opportunities, increased tribal revenues, upgrading of material welfare reputation of the tribe, and upgrading of living standards. The results supported past research on positive tourism impact [23]. When tourism development leads to positive impact, residents positively support tourism development Nunkoo and Ramkissoon [31]. In addition, the positive impact resulting from tourism positively influences the quality of life of the tribe, including indigenous people's enhancement of the sense of tribe, preservation of nature and culture, improvement of public facilities, increase of taxation and subsidies, increase of economic power, improvement of public security, and upgrading of tribal life. The findings were 
consistent with the research of Usher and Kerstetter [21] on residents in popular surfing areas of Nicaragua and the study result of Bakri and Jaafar [4] on residents in Langkawi Island of Malaysia, who demonstrated the positive effect of tourism development on local quality of life.

Although previous studies on tourism impact have proved to have a positive and negative impact on tourist destinations, it also has an impact on local quality of life. However, the focus of the study of tourism impact is whether the local residents agree with the development of tourism in the local area, just like the social exchange theory. When the residents think that the positive is greater than the negative, they will agree and accept the development of tourism in the local area, even if it has a negative impact. The above results are consistent with the previous studies [21] [22] [31]. However, this study also found that even though the indigenous people think that tourism has a negative impact on the tribe, in this case, they should actively maintain the habitat and quantity of wild animals and plants, natural original forest land, natural/cultural relics, natural landscape, and traditional culture. Because of the negative environmental impact brought by tourism, they are more concerned about the cleanliness of water and air, the environment and peace, the reduction of littering at will, the proper planning and use of land, and the reduction of disorderly buildings.

As Andereck, Valentine, Vogt and Knopf [6] pointed out, tourism can not only promote and promote the quality of life facilities, but also help the community achieve the ideal living environment. Therefore, from the above results, tourism development is not necessarily a negative impact, because it can help improve the quality of life of the tribe. This can be seen from the results of the model analysis of this study that only when tourism has a positive impact on the tribes can they hold a supportive attitude. On the contrary, negative tourism impact will not affect their attitude of supporting tourism development, that is, not supporting. The main contribution of this study is to verify that the attitude of indigenous people to support tourism in the tribe is not only influenced by tourism impact, but also directly influenced by the intermediary effect of the quality of life of the tribe.

\subsection{Conclusion}

According to the purposes and hypotheses of this study, after empirical analysis, this study came to the following conclusions. First, when indigenous people's perceived positive impact resulting from tourism is more significant, their perceived tribal quality of life will be higher and their support attitude toward tourism development will be more significant. Second, when indigenous people's perceived negative tourism impact is more significant, their perceived negative impact on tribal quality of life will be higher and they will tend to resist tourism development. Third, tribal quality of life is not only influenced by the tourism impact but also affects indigenous people's support attitude toward tourism development. In addition, it is a moderator between impact and support attitude. 


\subsection{Application}

First, regarding tourism impact, tourism certainly results in a positive impact, and thus indigenous peoples are not only satisfied with current tourism development but also agree with further tourism development. Nevertheless, negative impacts on the tribes should still be reduced. Hence, regarding tribal tourism development, the tribes can plan visits and ask tourists to park their cars outside of tribal areas to encourage tourists to visit the tribes by walking. They can install rubbish bins that are compatible with the environment to avoid the problems of garbage, traffic jams, and noise. In addition, with governmental subsidies, the tribes can reinforce cultural construction, such as the appearance of buildings, images, sculptures, and totems of indigenous culture, thus allowing youths in the tribes to approach Tsou culture and demonstrate the beauty of their culture in front of tourists.

At present, tourist attractions in Alishan refer to the great number of tourists in Alishan National Scenic Area and Shanmei tribe instead of indigenous tribes and cultural tourism. According to the findings of this study, the indigenous peoples showed a positive attitude towards tourism development, even though tourism could also lead to a negative impact. However, at present, the Shanmei tribe is the only successful case of development, and other tribes have not received enough attention to attract more tourists. Resources to increase the number of tourists are limited. In order to develop tourism, all tribes should reconsider and investigate tribal tourism resources and integrate their tourism resources in a complementary manner without overlap.

As to the research innovation, this study first recognized the impact of tourism on the quality of life of indigenous tribes and constructed the content and measures of tribal tourism impact on quality of life to serve as a reference for future research on tribal quality of life. In addition, the model and tribal impact content of this study could be used as criteria for future research on indigenous tribe tourism.

The researcher obtained knowledge in the areas under investigation by working for a tribal volunteer guide service and was thus able to acquire 827 samples. However, after statistical analysis, this study showed some limitations. The suggestions for future research were as follows. First, the research subjects were indigenous peoples instead of local Han people. However, there are Han people who have been living in the areas for a long period of time. Thus, future studies should also include Han people as subjects. Second, as to the questionnaire design, since most of the indigenous peoples were farmers, they encountered difficulty in responding to the monthly income item. Therefore, future studies should change it to annual income or total family monthly income in the survey.

\section{Acknowledgements}

This study was supported by a grant from National Social Science Foundation of China (No.18BMZ130). 


\section{Conflicts of Interest}

The authors declare no conflicts of interest regarding the publication of this paper.

\section{References}

[1] Chang, H.M. and Chang Liao, L.C. (2014) A Study of Indigenous Tribe Tourism Planning and Developing-Case by Huanshan in Taiwan. The Journal of International Management Studies, 9, 146-155.

[2] Huang, H.C., Liu, C.H. and Chang, H.M. (2015) Does Tourism Development Bring Positive Benefit to Indigenous Tribe? Case by Dongpu in Taiwan. Advances in Research, 4, 235-246. https://doi.org/10.9734/AIR/2015/15030

[3] Liou, G.-B. (2013)Ecotourism Cultural Impact Analysis. Ph.D. Thesis, Michigan State University, East Lansing, MI.

[4] Bakri, N.M. and Jaafar, M. (2015) An Analysis of Tourism Impacts on Residents Quality of Life. Advances in Environmental Biology, 9, 50-52.

[5] Michalkó, G., Bakucz, M. and Rátz, T. (2013) The Relationship between Tourism and Residents' Quality of Life: A Case Study of Harkány, Hungary. European Journal of Tourism Research, 6, 154-169.

[6] Andereck, K.L., Valentine, K.M., Vogt, C.A. and Knopf, R.C. (2007) A Cross-Cultural Analysis of Tourism and Quality of Life Perceptions. Journal of Sustainable Tourism, 15, 483-502. https://doi.org/10.2167/jost612.0

[7] Andereck, K.L. and Nyaupane, G. (2011) Development of a Tourism and Quality-of-Life Instrument. In: Budruk, M. and Phillips, R., Eds., Quality-of-Life Community Indicators for Parks, Recreation and Tourism Management, Springer, Dordrecht, 95-113. https://doi.org/10.1007/978-90-481-9861-0_6

[8] Uysal, M., Sirgy, M.J., Woo, E. and Kim, H. (2016) Quality of Life (QOL) and Well-Being Research in Tourism. Tourism Management, 53, 244-261. https://doi.org/10.1016/j.tourman.2015.07.013

[9] Yu, C.-P. (2011) Investigating Resident Attitudes toward Tourism Development: A Community Quality of Life Perspective. Ph.D. Thesis, Indiana University, Bloomington, IN.

[10] Nunkoo, R., Smith, S.L.J. and Ramkissoon, H. (2013) Residents' Attitudes to Tourism: A Longitudinal Study of 140 Articles from 1984 to 2010. Journal of Sustainable Tourism, 21, 5-25. https://doi.org/10.1080/09669582.2012.673621

[11] Lankford, S. and Howard, D. (1994) Developing a Tourism Impact Attitude Scale. Annals of Tourism Research, 21, 121-139. https://doi.org/10.1016/0160-7383(94)90008-6

[12] Park, E. and Kim, S. (2016) The Potential of Cittaslow for Sustainable Tourism Development: Enhancing Local Community's Empowerment. Tourism Planning \& Development, 13, 351-369. https://doi.org/10.1080/21568316.2015.1114015

[13] Allen, L.R. (1990) Benefits of Leisure Attributes to Community Satisfaction. Journal of Leisure Research, 22, 183-196. https://doi.org/10.1080/00222216.1990.11969824

[14] Boley, B.B., McGehee, N.G., Perdue, R.R. and Long, P. (2014) Empowerment and Resident Attitudes toward Tourism: Strengthening the Theoretical Foundation through a Weberian Lens. Annals of Tourism Research, 49, 33-50. https://doi.org/10.1016/j.annals.2014.08.005

[15] Gursoy, D., Jurowski, C. and Uysal, M. (2002) Resident Attitudes: A Structural 
Modeling Approach. Annals of Tourism Research, 29, 79-105. https://doi.org/10.1016/S0160-7383(01)00028-7

[16] Cascante, D.M. (2008) Consequences of Tourism-Based Growth on Rural Communities' Quality of Life: A Comparative Study of Liberia and La Fortuna, Costa Rica. Ph.D. Thesis, Indiana University, Pennsylvania State University, University Park, PA.

[17] Kim, K., Uysal, M. and Sirgy, M.J. (2013) How Does Tourism in a Community Impact the Quality of Life of Community Residents? Tourism Management, 36, 527-540. https://doi.org/10.1016/j.tourman.2012.09.005

[18] Perdue, R.R., Long, P.T. and Allen, L.R. (1990) Resident Support for Tourism Development. Annals of Tourism Research, 17, 586-599. https://doi.org/10.1016/0160-7383(90)90029-Q

[19] Sirakaya, E., Teye, S. and Sonmez, S. (2002) Understanding Residents' Support for Tourism Development in the Central Region of Ghana. Journal of Travel Research, 41, 57-67. https://doi.org/10.1177/004728750204100109

[20] Ko, D.-W. and Stewart, W.P. (2002) A Structural Equation Model of Residents' Attitudes for Tourism Development. Tourism Management, 23, 521-530. https://doi.org/10.1016/S0261-5177(02)00006-7

[21] Usher, L.E. and Kerstetter, D. (2014) Residents' Perceptions of Quality of Life in a Surf Tourism Destination: A Case Study of Las Salinas, Nicaragua. Progress in Development Studies, 14, 321-333. https://doi.org/10.1177/1464993414521525

[22] Hunter, W.C. (2011) Rukai Indigenous Tourism: Representations, Cultural Identity and Q Method. Tourism Management, 32, 335-348.

https://doi.org/10.1016/j.tourman.2010.03.003

[23] Ishii, K. (2012) The Impact of Ethnic Tourism on Hill Tribes in Thailand. Annals of Tourism Research, 39, 290-310. https://doi.org/10.1016/j.annals.2011.05.004

[24] Sirgy, M.J. and Cornwell, T. (2001) Further Validation of the Sirgy et al.'s Measure of Community Quality of Life. Social Indicators Research, 56, 125-143. https://doi.org/10.1023/A:1012254826324

[25] Sirgy, M.J., Rahtz, D.R., Cicic, M. and Underwood, R. (2000) A Method for Assessing Residents' Satisfaction with Community-Based Services: A Quality-of-Life Perspective. Social Indicators Research, 49, 279-316.

https://doi.org/10.1023/A:1006990718673

[26] Fornell, C. and Larcker, D.F. (1981) Evaluating Structural Equations Models with Unobservable Variables and Measurement Error. Journal of Marketing Research, 18, 39-50. https://doi.org/10.1177/002224378101800104

[27] Nunnally, J.C. and Bernstein, I.H. (1994) Psychometric Theory. 3rd Edition, McGraw-Hill, New York.

[28] Hair, J.F., Black, W.C., Babin, B.J. and Anderson, R.E. (2010) Multivariate Data Analysis. 7th Edition, Prentice Hall, Englewood Cliffs, NJ.

[29] Chin, W.W. (1998) The Partial Least Squares Approach for Structural Equation Modeling. In: Marcoulides, G.A., Ed., Modern Methods for Business Research, Lawrence Erlbaum Associates, Mahwah, NJ, 295-336.

[30] Venkatesh, V., Thong, J.Y. and Xu, X. (2012) Consumer Acceptance and Use of Information Technology: Extending the Unified Theory of Acceptance and Use of Technology. MIS Quarterly, 36, 157-178. https://doi.org/10.2307/41410412

[31] Nunkoo, R. and Ramkissoon, H. (2007) Residents' Perceptions of the Socio-Cultural Impact of Tourism in Mauritius. Anatolia: An International Journal of Tourism and Hospitality Research, 18, 138-145. https://doi.org/10.1080/13032917.2007.9687041 